\title{
População em situação de rua, voluntariado durante a pandemia: relato de experiência
}

\author{
Homeless population, volunteering during pandemic: experience report \\ Población callejera, voluntariado durante la pandemia: informe de experiencia
}

Édla Édna da Silva

ORCID: https://orcid.org/0000-0001-6096-2760

Universidade Federal de Pernambuco, Brasil E-mail: edllasilvaa1@gmail.com

Danielle Pereira de Lima

ORCID: https://orcid.org/0000-0001-5680-4372 Centro Universitário São Miguel, Brasil E-mail: fgadanielle@gmail.com Larissa Maria de Souza Silva

ORCID: https://orcid.org/0000-0003-2755-2254 Centro Universitário São Miguel, Brasil E-mail: larissafga13@gmail.com

Emyline Lucena Lima de Freitas Meira ORCID: https://orcid.org/0000-0002-7324-1679 Centro Universitário São Miguel, Brasil E-mail: emylinemeira@gmail.com

Alana Tainá Rodrigues Barbosa ORCID: https://orcid.org/0000-0002-4194-7837 Centro Universitário São Miguel, Brasil E-mail: alana02taina@gmail.com

Ithalo José Alves da Silva Cruz

ORCID: https://orcid.org/0000-0003-0485-4444

Universidade Federal de Pernambuco, Brasil E-mail: ithalojc@gmail.com

Fernanda Kelly do Nascimento Câmara Faustino ORCID: https://orcid.org/0000-0003-0543-8565 Centro Universitário Maurício de Nassau, Brasil E-mail: fisiofernandanascimento@gmail.com

Maria Alessandra Maciel da Silva ORCID: https://orcid.org/0000-0003-4678-9089 Centro Universitário São Miguel, Brasil E-mail: fgaalessandra@outlook.com.br Joyce Quirino da Silva ORCID: https://orcid.org/0000-0002-2815-4445 Universidade Federal de Pernambuco, Brasil E-mail: joycequirino021@gmail.com

Allana Nayara Soares da Silva ORCID: https://orcid.org/0000-0002-8586-6326 Universidade Federal de Pernambuco, Brasil E-mail: allananayara1326@gmail.com

Sándna Fabiolly Silva Fernandes ORCID: https://orcid.org/0000-0001-7339-4539

Universidade Federal de Pernambuco, Brasil E-mail: sandnafabiolly810@gmail.com

Allan Francisco Costa Jaques

ORCID: https://orcid.org/0000-0002-7097-5976

Universidade Federal de Pernambuco, Brasil E-mail:allanjaques1@gmail.com

Pablo Vinicius do Nascimento Pinto ORCID: https://orcid.org/0000-0001-7648-795X Instituto de Medicina Integral Professor Fernando Figueira, Brasil E-mail: pabloviniciusdonp@gmail.com

Edna Maria de Lima Silva

ORCID: https://orcid.org/0000-0001-9918-808X Universidade Grendal do Brasil, Brasil

E-mail: ednamarialimasilva@yahoo.com.br 


\author{
Stefani Ferreira de Oliveira \\ ORCID: https://orcid.org/0000-0002-4406-5119 \\ Universidade Federal de Pernambuco, Brasil \\ E-mail: stefaniioliveira2@gmail.com
}

\begin{abstract}
Resumo
Identificar através de um relato de experiência as demandas de saúde da população de rua, e relatar como são realizados os atendimentos dessa população que muitas vezes não recorrem ao SUS por vergonha, ou por medo de serem vítimas de preconceitos, destacando a importância do voluntariado neste período de pandemia. Trata-se de um relato de experiência de forma descritiva, sobre voluntariado Coletivo Unificados pela População em Situação de Rua, os atendimentos são realizados no Antigo Liceu de Artes e Ofícios, cedido pela Universidade Católica de Pernambuco (UNICAP) no Recife-PE. No início da pandemia o intuito era servir como ponto de higienização, o espaço cresceu em demanda e possibilidades, foram quase trinta mil atendimentos e mais de 1500 pessoas cadastradas. Existe uma resistência da parte das PSRs em irem às UPAs, pois nem sempre existe um bom acolhimento, e também há dificuldades socioeconômicas para o deslocamento. $\mathrm{O}$ trabalho voluntário com a população de rua durante a pandemia é um despertar de solidariedade e de empatia, é possível enxergar beleza nas ruas em meio ao caos e a tanta miserabilidade.
\end{abstract}

Palavras-chave: Pessoas em situação de rua; Cuidados de saúde; Atendimento integral.

\begin{abstract}
To identify, through an experience report, the health demands of the homeless population, and report how care is provided by this population, who often do not resort to the SUS out of shame, or fear of being victims of prejudice, highlighting the importance of volunteering in this pandemic period. This is an experience report in a descriptive way, about Collective volunteering Unified by the Homeless Population, the services are carried out at the Former Liceu de Artes e Ofícios, provided by the Catholic University of Pernambuco (UNICAP) in Recife-PE. At the beginning of the pandemic, the intention was to serve as a cleaning point, the space grew in demand and possibilities, there were almost thirty thousand assistances and more than 1500 people registered. There is resistance on the part of the PSRs to go to the UPAs, as there is not always a good reception, and there are also socioeconomic difficulties for moving. Volunteering with the homeless population during the pandemic is an awakening of solidarity and empathy, it is possible to see beauty in the streets amidst the chaos and misery.
\end{abstract}

Keywords: People in street situation; Health care; Full service.

\title{
Resumen
}

Identificar, a través de un relato de experiencia, las demandas de salud de la población sin hogar, e informar cómo es la atención que brinda esta población, que muchas veces no recurre al SUS por vergüenza, o miedo a ser víctimas de prejuicios, resaltando la importancia del voluntariado. en este período pandémico. Se trata de un relato de experiencia de forma descriptiva, sobre el voluntariado colectivo Unificado por la Población sin Hogar, los servicios se realizan en el Antiguo Liceu de Artes e Ofícios, brindado por la Universidad Católica de Pernambuco (UNICAP) en Recife-PE. Al inicio de la pandemia, la intención era servir como punto de limpieza, el espacio creció en demanda y posibilidades, hubo casi treinta mil asistencias y más de 1500 personas inscritas. Existe resistencia por parte de los PSR a acudir a las UPA, ya que no siempre hay una buena acogida, y también existen dificultades socioeconómicas para desplazarse. El voluntariado con la población sin hogar durante la pandemia es un despertar de la solidaridad y la empatía, es posible ver la belleza en las calles en medio del caos y la miseria.

Palabras clave: Personas en situación de calle; Cuidados de la salud; Servicio completo.

\section{Introdução}

A população em situação de rua (PSR) traz consigo incontáveis histórias de vida através de fatores psicossociais, de exclusão, por conflitos familiares, situação de drogadição, alcoolismo, e etc. Na rua encontram uma forma de refúgio, mas passam a enfrentar a dura realidade de estar ali. É importante elucidar que essas pessoas também têm seus direitos resguardados perante a constituição e integram a sociedade. Mas, muitas vezes se enxergam como coadjuvantes, consequentes da evidente exclusão e invisibilidade sofrida (Martins, 2020).

Segundo o IBGE (2021), somos cerca de 212 milhões de pessoas brasileiras, segundo a projeção da população, aproximadamente 222 mil brasileiros se encontram em situação de rua. No seu dia a dia, as Pessoas em Situação de Rua (PSR) sobrevivem de doações e de trabalhos realizados, como recolher material reciclável, gerando uma forma de garantir dinheiro e 
alimentos (Natalino, 2020). Viver em situação de rua é um problema que ultrapassa a falta de moradia. Ter uma casa significa ter segurança e sentimento de pertencimento, um lugar de bem estar emocional (Editorial, 2008).

Os artigos $1^{\circ}, 3^{\circ}$ e $5^{\circ}$ da Constituição Federal de 1988 prescrevem como fundamento do Estado a dignidade da pessoa humana e, como objetivos, a erradicação da pobreza e da marginalização e a redução das desigualdades sociais, além da promoção do bem-estar de todos, sem preconceitos de qualquer natureza. Apesar disso, a realidade das pessoas em situação de rua é bem diferente: alvos de violência, como chacinas e extermínios, espancamentos, retirada dos pertences, óbice no acesso aos serviços e espaços públicos, entre outras ações de cunho higienista, como a expulsão das regiões centrais da cidade (Ministério, 2020).

A Portaria $n^{\circ} .122$ (Ministério, 2011) foi importante porque definiu as diretrizes de funcionamento e organização das equipes de Consultório na Rua (eCR), estrutura que integra a atenção básica da Rede de Atenção Psicossocial e desenvolve ações de Atenção Básica em Saúde de acordo com os fundamentos e as diretrizes definidas na Política Nacional de Atenção Básica. Segundo essa Portaria, as eCR devem ser multiprofissionais e lidar com os diferentes problemas e necessidades de saúde da população em situação de rua, incluindo atividades de busca ativa e cuidado aos usuários de álcool, crack e outras drogas (Ministério, 2020).

Costa (2005), relata que as pessoas que vivem em situação de rua têm acesso limitado aos serviços de saúde, acompanhados de uma gama de entraves, a exigência de comprovação de residência nos tratamentos de saúde, aplicados a regras que não levam em consideração as condições de vida destes indivíduos, e o despreparo dos profissionais para o acolhimento a esse grupo.

A População em Situação de Rua enfrenta dificuldade de acesso a serviços, como saúde e assistência social, o que tem como consequência maior índice de doenças preveníveis e tratáveis, visto que, muitas vezes, não há continuidade do tratamento, ou ainda existe deficiência na realização de exames e cuidados básicos, inclusive no que se refere à higiene pessoal (Hino et al., 2018).

De acordo com Bottil et al. (2009) é importante destacar que a população em situação de rua não apresenta aspectos homogêneos. Assim a diversidade é a característica própria dessa população no que se refere às origens sociais, trajetórias de vida, tempo na rua, presença de doenças e deficiências, pessoas sozinhas ou em grupos de amigos ou família. Sendo fator que dificulta as generalizações e as metodologias e coloca a complexidade do fenômeno da população de rua e da imprecisão e ambiguidade do termo.

O Brasil possui limitado conhecimento sobre as condições de vida, de trabalho, experiências associativas e organizativas e conquistas no âmbito das políticas públicas de trabalho, moradia, assistência e inclusão social do grupo social em questão. Diante da impossibilidade de isolamento, da aquisição de alimentos e água e das limitações em realizar medidas preventivas, as ações de cuidado oferecidas pelos gestores para limitar a disseminação do vírus, ainda nessa população, são pouco eficazes. (De Paula et al., 2020)

Embora haja avanços no acesso e na produção do cuidado à PSR no SUS, a precarização no acesso e na violação do direito à saúde dessa população tem sido constantemente relatada por pesquisadores da área (Honorato \& Oliveira, 2020. APUD, Paula \& Laura, 2018).

Em dezembro de 2019 a China informou à OMS sobre o surto de uma nova doença, semelhante a uma pneumonia. Essa doença, transmitida pelo novo coronavírus, foi denominada COVID-19 (Wu et al., 2020), o que tornou uma pandemia, trazendo consigo muitas dificuldades, com isso muitas famílias foram parar nas ruas devido ao desemprego, alguns projetos voluntários que atendiam as PSRs tiveram que parar, devido aos voluntários estarem em grupos de risco, e a partir daí surgiu a ideia de juntar os voluntários disponíveis e criar um coletivo, conhecido como Unificados pela População de Rua. Inicialmente, o projeto começou com alimentação, café da manhã e jantar. Depois que o projeto cresceu, as parcerias aumentaram e começaram a doar 
roupas limpas e banhos, o projeto continuou crescendo e formamos uma equipe de saúde para atender a população em situação de rua.

O objetivo desse artigo é apresentar, por meio de um relato de experiência, as demandas de saúde da população de rua, e relatar como são realizados os atendimentos à estes. Destacando, dessa forma, a importância do voluntariado no período de pandemia, o qual houve a necessidade de adaptação ao novo normal, dando oportunidade para visionar a perspectiva do próximo com mais empatia, tendo em consideração que a pandemia apresentou de forma escancarada as desigualdades sociais.

\section{Metodologia}

Trata-se de um artigo do tipo relato de experiência, estudo descritivo e de abordagem qualitativa, em que descreve precisamente uma dada experiência que possa contribuir de forma relevante para a área de atuação. Essa vivência tem a oportunidade de contribuir com a discussão, a troca e a proposição de ideias para a melhoria do cuidado em saúde (UFJF, 2017). Para tal, a abordagem qualitativa foi utilizada tendo em vista que a mensuração dos resultados não podem ser representados de forma estatística (Galvão et al, 2021 APUD Minayo, 2012).

Segundo Lucke e André (1986), dentre os estudos qualitativos temos as diretrizes gerais orientadores por meio de pontos descritivos e reflexivos, sendo esta a obra escolhida para corroborar um suporte metodológico. Dessa maneira, o acompanhamento e discussão das contribuições foram realizadas em conjunto para colaborar com o presente estudo, sendo uma abordagem empírica, crítica e reflexiva acerca da experiência dos autores.

O presente relato foi construído a partir das práticas vivenciadas no voluntariado Coletivo Unificados pela População em Situação de Rua, realizados no Antigo Liceu de Artes e Ofícios, cedido pela Universidade Católica de Pernambuco (UNICAP) no município do Recife-PE. Além dos voluntários, parceiros como o projeto Ronda de Direitos e a Vive Rua, da ONG Samaritanos, ReconstRua, do Reconstrua e a Liga Acadêmica de Infectologia, ambos da Universidade Católica de Pernambuco (UNICAP) e a Secretaria de Saúde da Prefeitura do Recife auxiliam nas atividades realizadas.

As programações aqui relatadas correspondem ao período compreendido entre os meses de março de 2020 e março de 2021, sub-equipes de organização foram montadas e distribuídas, alocadas por afinidade e visando melhor divisão de trabalho, podendo o voluntário mudar de equipe e/ou função quando necessário ou lhe for cabível.

\section{Resultados}

Podem fazer parte do Coletivo Unificados pela PSR qualquer indivíduo de carga horária disponível, interessado e que tenha realizado sua inscrição por meio de link digital público, exposto na descrição das redes sociais. A divulgação inicial do projeto se deu pela mesma plataforma, como o Instagram, que atualmente possui cerca de 10 mil seguidores em seu perfil. Inicialmente, o objetivo foi suprir as necessidades mais emergenciais, arrecadando produtos de higiene, alimentos e recursos financeiros para a aquisição desses materiais para ponto de higienização, logo o espaço cresceu em demanda e possibilidades, foram quase trinta mil atendimentos e mais de 1500 pessoas cadastradas.

O cadastro da PSR é realizado de forma online, no próprio ponto, onde consta foto e as seguintes informações de identificação pessoal: nome, idade, se está em situação de rua, onde encontrá-lo, se é usuário de drogas, se teve acesso ao auxílio emergencial, se tem algum problema de saúde e, se for mulher, se está grávida.

Toda a PSR tem direito ao café da manhã, banho e roupas limpas, três vezes durante a semana são dispostos atendimento jurídico, em parceria com o projeto Ronda de Direitos da ONG Samaritanos, e podem contar com atendimentos em saúde. Nisso, o Coletivo Unificados realiza o atendimento em Saúde, também três vezes durante a semana: terças-feiras, quintas-feiras e sábados. Ademais, existe um cartão de acompanhamento diário para pessoas que têm doenças crônicas como a Hipertensão 
Arterial Sistêmica (HAS), Diabetes Mellitus (DM), Saúde Mental e usuários de drogas, realizando as aferições, acompanhamentos, curativos e tirando dúvidas em saúde.

O Coletivo Unificados é composto de parcerias e voluntários, estes que doam máscaras e álcool a 70\%, a prefeitura do Recife que vem auxiliando com algumas doações e, também, foi articulada como uma parceria com o Consultório na Rua, serviço da Secretaria de Saúde do Recife, prestando a testagem rápida do COVID-19, isso nos mostra que o poder público e a sociedade civil conseguem garantir os direitos e assistência à saúde de quem precisa pela união de esforços. Em outro momento, em parceria com ReconstRua, do Reconstrua UNICAP, e a Vive Rua, da ONG Samaritanos, juntaram-se numa ação à Liga Acadêmica de Infectologia da Universidade Católica de Pernambuco (UNICAP) e à prefeitura do Recife, que enviou um mamógrafo para atender mulheres em situação de rua (Figura 1) ou de vulnerabilidade acima de 50 anos.

Figura 1 - Mamógrafo Móvel.

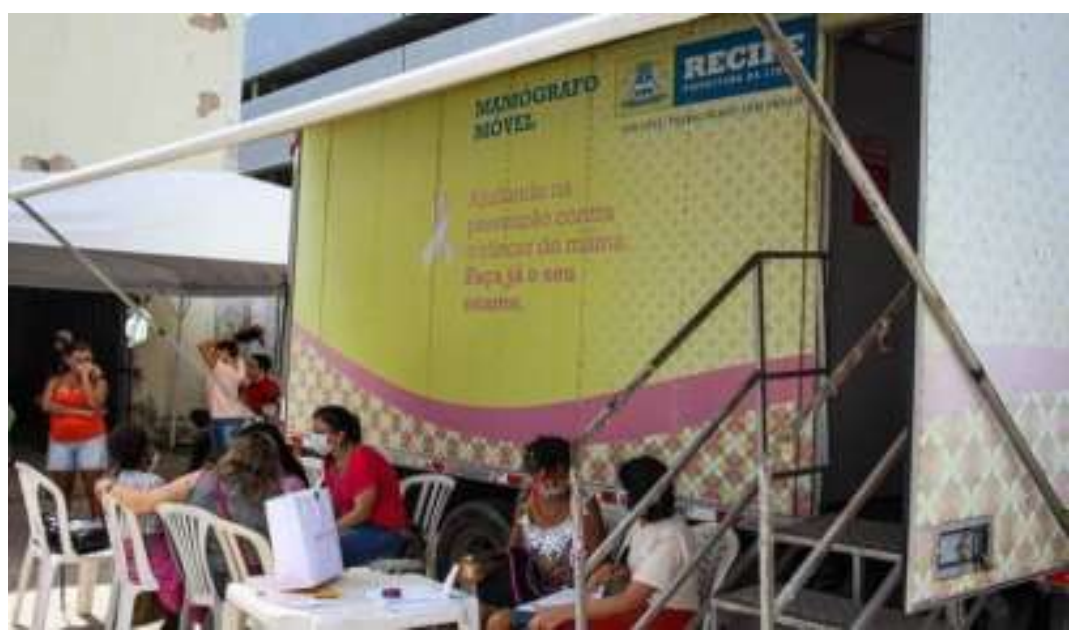

Fonte: Unificados PSR (2021).

Uso do Mamógrafo Móvel ofertado pela prefeitura do Recife, atendendo as mulheres em vulnerabilidade e em situação de rua.

A demanda dos atendimentos em saúde são homens entre 30 a 60 anos, uma faixa etária bem variada, são realizados entre 15 e 20 atendimentos em saúde por dia. Quando é necessário são encaminhados para Upinha do Pilar para atendimento de saúde, por lá existir um Consultório de Rua; outros encaminhamentos são para Gouveia de Barros, quando os casos são de Infecções Sexualmente Transmissíveis (ISTs)/Aids; também encaminhamos aos CAPS para tratamento de álcool e outras drogas. E, em caso de urgência, para UPAs e Policlínicas, a mais frequente é a Policlínica Agamenon Magalhães de Afogados, no mesmo município.

Existe uma resistência da parte da PSR em irem às UPAs, pois lá nem sempre existe um bom acolhimento, além das existentes dificuldades socioeconômicas para o deslocamento. Levando em consideração a adesão ao tratamento, que muitas vezes não é fácil, a PSR não tem uma rede de apoio concreta. Assim, as mulheres grávidas em situação de rua aparecem com muita frequência e quando colaboram é tentando o acompanhamento da gestação até o puerpério, período importante e que requer extremos cuidados. Ainda, a população transsexual também faze parte da demada do Coletivo e sempre se policiam, fazendo testes rápidos de HIV e a aquisição de preservativos. 


\section{Discussão}

Apesar da existência das políticas públicas de saúde direcionadas a população de rua, muito ainda deve ser feito para a garantia da saúde destes. Durante a pandemia o trabalho voluntário veio ganhando força, afinal, acolher e fazer o bem, sem preconceito é uma forma de prestar atenção e cuidado para aqueles que mais precisam. Como consequência, vê-se o outro biopsicossocialmente bem e cheio de gratidão, reafirmando o propósito do Coletivo e enfatizando que a cura é algo além da atenção médica convencional.

Pode haver uma série de atividades que fazem o ser humano sentir-se saudável, mas o voluntariado o permite sentir-se bem consigo mesmo, é impressionante como se desdobram para cuidar do outro, o outro até então desconhecido. Entretanto, o voluntariado veio um sinal de esperança durante a pandemia, as pessoas que já viviam em vulnerabilidade socioeconômica foram jogadas à própria sorte. É de conhecimento coletivo que os profissionais de saúde estão na linha de frente desde o início, não apenas no âmbito hospitalar, mas cabe-se elucidar também a sua participação em pontos de higienização, oferecendo cuidados (Figuras 2) e aplicando o letramento em saúde durante a pandemia, compartilhando saberes de como lavar as mãos, higienizarse com álcool e realizar o uso correto das máscaras de proteção.

Figura 2 - Atuação de profissionais de saúde voluntários.

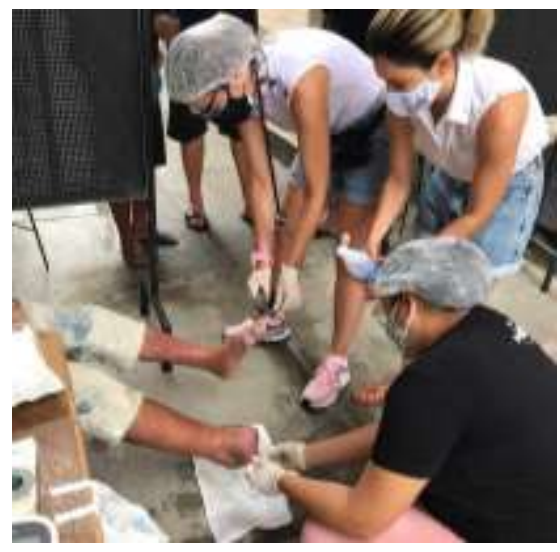

Fonte: Unificados PSR (2021).

Subgrupo de atendimento com os profissionais de saúde voluntários, realização da limpeza e de curativo em pé amputado infeccionado e com presença de miíase em um dos assistidos pelo Unificados PSR.

O trabalho voluntário com a população de rua durante a pandemia é um despertar de solidariedade e de empatia (Figura 3), é possível enxergar beleza nas ruas em meio ao caos e a tanta miserabilidade. É nos momentos difíceis, naqueles em que a esperança está morrendo que podemos atuar como protagonistas de grandes realizações. Por esse fator, sem dúvidas, o voluntariado é a resposta da prece de muitos ali presentes. Assim, espera-se que todos possam desfrutar de um país de igualdade, com acesso a Universalidade, Equidade e Integralidade, princípios que fazem o Sistema Único de Saúde no Brasil ser o que é hoje. 
Figura 3 - Limpeza de feridas.

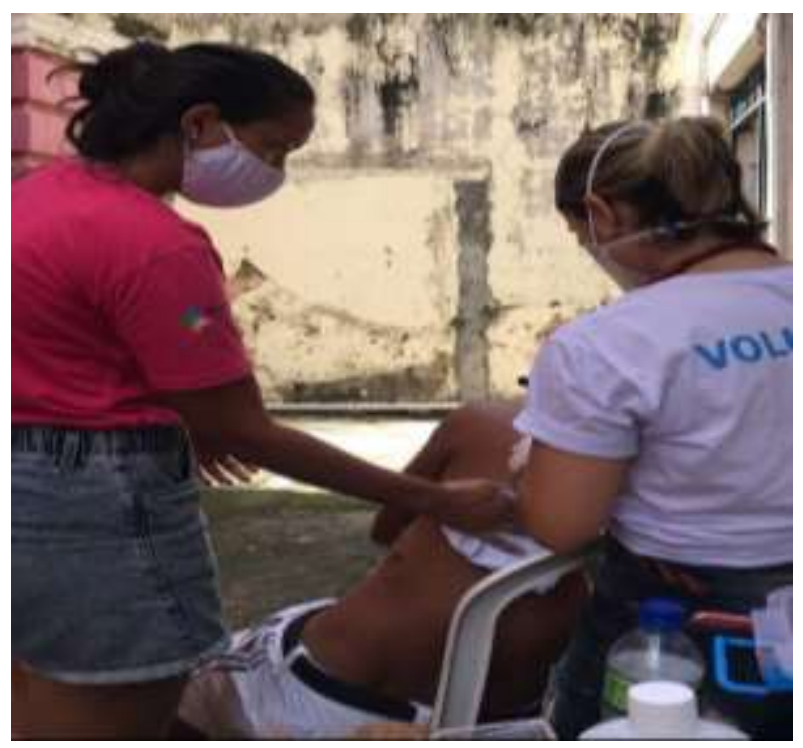

Fonte: Unificados PSR (2021).

Atendimento dos profissionais de saúde voluntários na limpeza de feridas causadas por perfuramento de faca em um dos usuários do projeto Unificados PSR.

\section{Considerações Finais}

As demandas de saúde da PSR dizem respeito a fatores que abrangem o acompanhamento abrangente e continuado de doenças crônicas e comorbidades, promoção, prevenção e vigilância em saúde e colaboração intersetorial, funções estas cabíveis ao plano de Atenção Primária à Saúde do município.

Dentre os atendimentos realizados, houve-se grande adesão e bom retorno. O papel do voluntário nesse período superou as expectativas antes discutidas, indo além do que foi inicialmente proposto, por meio dele foi possível construir laços de amizade e levar esperança às mais diversas situações encontradas. No que se diz empatia segundo Titchener já em 1909 (Sampaio et al., 2009) conhecer a consciência de outra pessoa e racionalizar de maneira análoga, temos que esse conceito se fez um combustível de vida, atemporal mesmo em contexto sanitário, aumentando a capacidade individual de compreender a si e ao outro.

Em detrimento disso, é esperado que mais contribuidores se interessem em produzir sobre a temática, envolvendo estudos objetivos de caráter exploratório e descritivo, visando respostas do "como" e "porquê" sobre os eventos inseridos na vida real.

\section{Referências}

Bottil, N. et al. (2011), Condições de saúde da população de rua da cidade de Belo Horizonte. Brazilian Journal of Mental Health, 1(2), 162-176.

Ministério da Saúde. Portaria n 122. (2012). Diretrizes de organização e funcionamento das equipes de Consultório na Rua.

Ministério da Economia. Instituto Brasileiro de Geografia e Estatística. (2020). Projeções da população: Brasil e unidades da Federação.

Ministério da Mulher, da Família e dos Direitos Humanos. Conselho Nacional dos Direitos Humanos (2020). Direitos das pessoas em situação de rua. p. 144.

Ministério da Saúde. Secretaria Executiva, (2000). Sistema Único de Saúde: Princípios e conquistas. https://bvsms.saude.gov.br/bvs/publicaco es/sus_principios.pdf

Costa, A. P. M. (2005) População em situação de rua: contextualização e caracterização. Revista Virtual Textos e contextos, 4(1), 1-15.

De Paula, H. C. et al (2020). Sem isolamento: etnografia de pessoas em situação de rua na pandemia de Covid-19. Rev. Bras. Enferm., 73(suppl 2), 1-8. 
Hino, P. et al., (2018) Pessoas que vivenciam situação de rua sob o olhar da saúde. Revista Brasileira de Enfermagem. 71(sup.1) p. 684-692.

Honorato, B. E. F. \& Oliveira, A. C. S. (2020). População em situação de rua e COVID-19. Rev. Adm. Púlica, 54(4), 1064-1078.

Marques, S. R. L., \& Lemos, S. M. A. (2017). Instrumentos de avaliação do letramento em saúde: revisão de literatura. Audiol. Commun. Res., 22 e.1757 1-12.

Martins, G. V. J. (2021). População de Rua e Covid-19: reflexões acerca de cidadania e direito à informação. https://www.encenasaudemental.com

Natalino, M. A. C. (2020). População em situação de rua cresce e fica mais exposta à Covid-19. Estimativa da população em situação de rua no Brasil. Retrieved junho, 2020, from https://www.ipea.gov.br/portal/index.php?option=com_content\&view=article\&id=35811

Paiva, K. S. P. et al. (2016). Direito à saúde da população em situação de rua: reflexões sobre a problemática. Ciência e saúde coletiva. $21(8)$ p. $2595-2606$.

Sampaio, H. A. C. et al. (2015). Letramento em saúde de diabéticos tipo 2: fatores associados e controle glicêmico. Ciênc. e Saúde Coletiva, 20 (3), 865-874.

Sampaio, L. R. et al. (2009). Revisão dos aspectos conceituais, teóricos e metodológicos da empatia. Psicol. cienc. prof., 29(02).

Silva, C. C. et al. (2015) Práticas de cuidado e população em situação de rua: o caso do consultório de rua. Saúde debate, 39(spe), $246-256$.

Silva, T. D. et al., in:Brasil, Ministério da Educação. (2020). População em situação de rua em tempos de pandemia: um levantamento de medidas municipais emergenciais. RC IPEA, 74, 1-26.

The PLoS Medicine. (2008). Homelessness is not just a housing problem. PloS Medicine, 5 (12).

UFJF. (2017). Estágio em nutrição em saúde coletiva: Instrutivo para elaboração de relato de experiência. Instituto de ciências e vida - departamento de nutrição, 1-2. https://www.ufjf.br/nutricaogv/files/2016/03/Orienta\%C3\%A7\%C3\%B5es-Elabora\%C3\%A7\%C3\%A3o-Relato-de-Experi\%C3\%AAncia.pdf

WU F., et al. (2020). A new coronavirus associated with human respiratory disease in China. Nature, 579(7798), $265-269$.

Minayo, M. C. S. (2012). Análise qualitativa: teoria, passos e fidedignidade. Ciência \& Saúde Coletiva, 17(3), 621-626.

Ludke, M.., \& André, M. E. D. A. (2013). Pesquisas em educação: uma abordagem qualitativa. São Paulo: E.P.U. 35-44.

Yin, R. K. (2015). O estudo de caso. Bookman. 